\title{
Determining Significant Factors Affecting Vaccine Demand and Factor Relationships Using Fuzzy DEMATEL Method
}

\author{
İkbal Ece Dizbay ${ }^{(\bowtie)}($ (]) and Ömer Öztürkoğlu (1) \\ Yasar University, Bornova, İzmir, Turkey \\ ece.dizbay@yasar.edu.tr
}

\begin{abstract}
Even though deadly effects of outbreaks such as SARS, H1N1, EBOLA and COVID-19 took the attention of the community, generating $100 \%$ vaccination uptake from people who are expected to be affected by such outbreaks is almost impossible. Hence, determining the actual vaccine demand for typical viruses and reaching this population are becoming important issues to prevent from spreading such viruses like wildfire. Many countries have been forecasting vaccine demand according to birth rates. However, factors such as district-level per capita income, literacy rate, urbanization, and some other factors should also be considered for more accurate forecasts. There is another factor affecting countries' vaccine demand; some of the vaccines that WHO recommends are included in the national immunization programs, while others are only recommended. Thus, this study first aims to explore the most significant factors that affect the demand of vaccines that are not included in national immunization campaigns then to present the cause and effect relationships among the factors using the fuzzy DEMATEL method to provide insights to managers for better vaccine demand forecast and to increase vaccine uptake. According to the analysis results, immunization related beliefs is the most important factor among others included in this research.
\end{abstract}

Keywords: Vaccine demand - Factor relationship - Fuzzy DEMATEL

\section{Introduction}

According to WHO [1], vaccines protect 2.5 million lives from deadly diseases every year. Not only children but also pregnant women and elderly people are vaccinated regularly against some diseases. In addition to these, people from every age can be vaccinated against some outbreaks of vaccine-preventable diseases such as influenza pandemic. Millions of people are vaccinated every year but also WHO [2] estimates that nearly 19.4 million babies, under the age one, could not receive scheduled basic vaccines. By efficiently vaccinating the target population, eliminating deadly diseases is possible. As an example of the results of deadly outbreaks, in the 18th century, 400,000 people were dying annually in Europe from smallpox disease and thousands of people went blind. Even if the development of the smallpox vaccine began about 1774, in 1967, the illness still was not under control. In 1967, a global campaign began and in 1980 WHO announced that the world was free of this disease [3]. Another example of a

(C) The Editor(s) (if applicable) and The Author(s), under exclusive license

to Springer Nature Switzerland AG 2021

C. Kahraman et al. (Eds.): INFUS 2020, AISC 1197, pp. 682-689, 2021.

https://doi.org/10.1007/978-3-030-51156-2_79 
deadly disease outbreak of this age is the novel Coronavirus (COVID-19). By the beginning of 2020, COVID-19 escalated into a real epidemic. In just 3.5 months, more than 1.3 million people around the world were infected and more than 126,500 people died from the outbreak [4]. In addition to health-related risks, OECD has announced that the world economy is at risk [5]. To decrease the expected impact of this crisis, scientists are working on the COVID-19 vaccine, but unfortunately releasing a new vaccine to the market takes a long time. Even if the vaccine is released to the market, estimating the demand for this vaccine and meeting this huge demand in a short period is difficult.

Children are generally vaccinated against some of the childhood diseases through national immunization programs, conducted by governments or non-governmental organizations. However, some vaccines are not included in national immunization programs even if they are suggested by WHO or other health organizations. As an example of Turkey, most of the vaccines recommended by WHO are included in the National Immunization Program, except Rotavirus, Influenza and Meningococcal conjugate. The main contribution of this study is presenting the macro-level insights about the effects of several factors on demand of such vaccines and their relations. The structure of the remainder of this paper is as follows: In Sect. 2, the literature review of the vaccine demand factors is given. In Sect. 3 and 4 Fuzzy-DEMATEL Method and its application is presented. Finally, managerial insights, limitations and concluding remarks are presented in Sect. 5.

\section{Literature Review}

There are several classifications made by researchers to classify determinants of vaccine uptake. Ghosh et al. [6] classify immunization coverage factors in two categories according to their literature review, supply-side and demand-side. According to their research demand-side factors covers birth order, sex, maternal education, and employment status, occupation type, immunization related beliefs, mother's health knowledge, health-seeking behavior, household wealth index, religion, and caste. Phillips et al. [7] categorized vaccine coverage determinants for low and middleincome countries; facility readiness, decision to vaccinate and mother able.

For this study, six factors that affect vaccine demand were determined; district-level per capita income, literacy rate of the district, immunization-related-beliefs, healthcare workers' knowledge, urbanization, and special immunization campaigns or strategies. Rammohan et al. [8] concluded that district-level per capita income is an important factor to have better immunization outcomes in India. Another study showed that children living in urban areas in India and the lowest wealth quartile have lower coverage [9]. For the effect of illiteracy rate, Kibreab et al. [10] conclude that mothers' education level has a positive effect on immunization outcomes. Contrary to this result, some researchers concluded that mothers' education level does not affect immunization coverage [11]. Arokiasamy et al. [12] concluded that having an illiterate mother or father affects immunization coverage. In Turkey Ak1s et al. [13] concluded that parents with a higher educational level are more positive about vaccination. Immunizationrelated beliefs or disbeliefs are another reason that decreases immunization coverage. 
These beliefs can be due to the adverse effects of vaccination, recommendations of healthcare professionals, knowledge, social influences, information about the vaccine, etc. For the influenza vaccination in Turkey, Ciblak et al. [14] surveyed the pharmacist and occupational physicians and they indicate that disbelief in the effectiveness of the influenza vaccine is effecting vaccine uptake negatively. Sissoko et al. [15] indicated that the place of residence (living in urban or rural areas) is significantly associated with non-vaccination. There are some contrary opinions about this relation; some researchers concluded that children living in urban residences are vaccinated less than children living in rural areas [16]. Health workers' knowledge about vaccines is another factor for vaccine uptake. If there is not enough reliable data about a new vaccine, health workers hesitate about vaccine uptake. When the Rotavirus vaccine was first released, healthcare workers were reluctant to recommend it due to its side effects. After several papers published about this vaccine, some of the health workers begun to recommend it. Furthermore, several studies indicated that vaccination campaigns affect vaccine demand. Shea et al. [17] concluded that mass media campaigns can be effective but this effect is due to access to media.

\section{Research Methodology}

This study specifically focuses on vaccines that are suggested by WHO but are not mandatorily applied to children. Thus, the parents trigger the demand for these types of vaccines. Because of this characteristic, forecasting demand for these types of vaccines is erratic. Therefore, the healthcare managers or healthcare product distributors face a critical decision about how much vaccines should be ordered to avoid from stock out and minimizing wastes. Hence, this study aims to present macro-level insights into the effects of several factors on vaccine demand.

As mentioned in the previous section, six factors were determined from the literature those are expected to affect vaccine demand: Immunization-related beliefs (F1), District-level per capita income (F2), Urbanization (F3), Healthcare workers' knowledge about the vaccines (F5), and Special immunization campaigns or strategies (F6). As mentioned in the literature that each factor may have a different impact on demand. Moreover, they may also affect each other. Therefore, in this study, (1) the significance of each factor's influence on the demand and (2) the cause and effect relationship among the factors was identified. Hence, one of the most commonly used MCDM (Multi-Criteria Decision-Making) methods called DEMATEL (Decision Making Trial and Evaluation Laboratory) was used in this study because of it both ranks the factors according to their importance and causal relationships between them. Due to the vagueness of human thoughts and language in decision-making, several studies presented the strength of using fuzzy variables in the assessments in the DEMATEL approach; Wu and Lee [18]; Lin and Wu [19]; Feng and Ma [20]. In this study, the Fuzzy-DEMATEL approach was implemented, which was first proposed by $\mathrm{Wu}$ and Lee [18] and Lin and Wu [19] and later corrected by Mokhtarian [21]. The basic steps of the implemented Fuzzy-DEMATEL approach are as follows: 
Step 1: Determine the influencing factors. In this study, the factors are F1, F2, ., F6.

Step 2: Design a semantic scale that shows the degree to what extent a factor influences another factor through pairwise-comparison. Similar to Wu and Lee [18], five fuzzy linguistic scales with triangular fuzzy members was implemented as demonstrated in Table 1. The invited experts are asked to evaluate the influence of each factor using this scale.

Table 1. The fuzzy linguistic scale

\begin{tabular}{l|l|l}
\hline Linguistic terms & Triangular fuzzy numbers & Crisp numbers \\
\hline Very high influence (VH) & $(0.75,1.00,1.00)$ & 4 \\
\hline High influence (H) & $(0.50,0.75,1.00)$ & 3 \\
\hline Low influence (L) & $(0.25,0.50,0.75)$ & 2 \\
\hline Very low influence (VL) & $(0,0.25,0.50)$ & 1 \\
\hline No influence (No) & $(0,0,0.25)$ & 0 \\
\hline
\end{tabular}

Step 3: Obtain the initial relation matrices consisting of linguistic terms for each expert.

Step 4: The linguistic terms are converted into the triangular fuzzy numbers given in Table 1.

Step 5: Defuzzify the fuzzy numbers using the CFCS (Converting Fuzzy date into the Crisp Scores) method proposed by Opricovic and Tzeng [22]. Then combine experts' evaluations using their crisp values.

Step 6: Calculate the initial direct relation (Z), normalized direct relation (X) and comprehensive impact matrices (T). The comprehensive impact matrix shows the total impact relationship among the factors.

Step 7: Calculate the influence $\left(D_{i}\right)$, the affected $\left(R_{i}\right)$, the center $\left(P_{i}\right)$ and the cause $\left(E_{i}\right)$ degrees for each factor $i$ to identify the significance of the factors and the cause and effect relationship between them, where;

$$
\begin{aligned}
& \mathrm{P}_{\mathrm{i}}=\mathrm{D}_{\mathrm{i}}+\mathrm{R}_{\mathrm{i}} \\
& \mathrm{E}_{\mathrm{i}}=\mathrm{D}_{\mathrm{i}}-\mathrm{R}_{\mathrm{i}}
\end{aligned}
$$

\section{Implementation and Results}

For the implementation phase, five experts were invited to determine the influences of each factor. Four of them have a medical background and the other has a business background. All of the experts that have medical background have at least five-year experience in vaccination, immunization or public health. The non-medical expert has experience in forecasting, inventory management, logistics, and healthcare engineering 
studies. To provide insights into the influence of factors on vaccine demand forecasting, the thoughts of these experts can be used. The characteristics of the experts are shown in Table 2. Because of confidentiality, their names and institutions were not shared in this study.

Table 2. The characteristics of the experts

\begin{tabular}{l|l|l|l|l}
\hline Expert ID & Degree & Tittle & Academic/Practice & Experience year \\
\hline Expert \#1 & Medical Doctor & Professor & Both & 41 years \\
\hline Expert \#2 & Medical Doctor & - & Practice & 30 years \\
\hline Expert \#3 & Midwifery & Asst. Prof. & Both & 26 years \\
\hline Expert \#4 & Medical Doctor & - & Practice & 12 years \\
\hline Expert \#5 & Industrial Eng. & Assoc. Prof. & Academic & 16 years \\
\hline
\end{tabular}

Experts' pairwise comparisons were collected through a face-to-face interview. After the goal of the study was explained, each factor was introduced in detail. Next, the assessment scale and the procedure were explained. Table 3 shows the Expert \#3's linguistic assessment.

Table 3. The linguistics assessment of Expert \#3

\begin{tabular}{l|l|l|l|l|l|l}
\hline Expert \#3 & F1 & F2 & F3 & F4 & F5 & F6 \\
\hline F1 & NO & NO & NO & NO & VL & VH \\
\hline F2 & VH & NO & VH & H & VH & H \\
\hline F3 & VH & NO & NO & H & H & VH \\
\hline F4 & VH & NO & NO & NO & VL & VL \\
\hline F5 & VH & NO & NO & VH & NO & VH \\
\hline F6 & VH & NO & NO & H & NO & NO \\
\hline
\end{tabular}

After implementing the fuzzy-DEMATEL procedure described briefly in the previous section, the initial direct relation $(Z)$ and comprehensive impact matrices $(T)$ were obtained and given in Tables 4 and 5.

Table 4. The direct relation matrix

\begin{tabular}{l|l|l|l|l|l|l}
\hline Z & F1 & F2 & F3 & F4 & F5 & F6 \\
\hline F1 & 0.033 & 0.051 & 0.033 & 0.161 & 0.370 & 0.409 \\
\hline F2 & 0.543 & 0.033 & 0.759 & 0.339 & 0.802 & 0.586 \\
\hline F3 & 0.409 & 0.418 & 0.033 & 0.339 & 0.718 & 0.759 \\
\hline F4 & 0.915 & 0.077 & 0.087 & 0.033 & 0.389 & 0.279 \\
\hline F5 & 0.847 & 0.062 & 0.169 & 0.669 & 0.033 & 0.707 \\
\hline F6 & 0.915 & 0.116 & 0.077 & 0.759 & 0.316 & 0.033 \\
\hline
\end{tabular}


Table 5. The comprehensive impact matrix with the influence and the affected degrees.

\begin{tabular}{l|l|l|l|l|l|l|l}
\hline T & F1 & F2 & F3 & F4 & F5 & F6 & Di \\
\hline F1 & 0.2026 & 0.0446 & 0.0475 & 0.1822 & 0.2169 & 0.2475 & 0.9414 \\
\hline F2 & 0.7041 & 0.1023 & 0.3394 & 0.4605 & 0.5698 & 0.5626 & 2.7385 \\
\hline F3 & 0.6120 & 0.2029 & 0.1101 & 0.4223 & 0.4976 & 0.5489 & 2.3938 \\
\hline F4 & 0.5291 & 0.0644 & 0.0770 & 0.1712 & 0.2757 & 0.2723 & 1.3897 \\
\hline F5 & 0.6344 & 0.0794 & 0.1180 & 0.4353 & 0.2271 & 0.4521 & 1.9463 \\
\hline F6 & 0.5978 & 0.0843 & 0.0861 & 0.4175 & 0.2937 & 0.2231 & 1.7025 \\
\hline Ri & 3.2800 & 0.5779 & 0.7781 & 2.0890 & 2.0808 & 2.3064 & \\
\hline
\end{tabular}

Using the $D_{i}$ and $R_{i}$ values obtained in Table 5, the center $\left(P_{i}\right)$ and the cause $\left(E_{i}\right)$ degrees were calculated for each factor $i$ using Eqs. 1 and 2. Hence, the centrality degree $\mathrm{Pi}$ indicates the importance of the factors where the highest $P i$ shows the most important factors. Moreover, the cause degree $E_{i}$ is used to determine which factors are cause or effect. Hence, the factors that have negative $E_{i}$ values are the effect and the positive ones are the cause factors. Table 6 demonstrated the centrality and the cause degrees for each factor as well as their importance and groups.

Table 6. The importance order and the groups of factors according to the centrality and cause degrees.

\begin{tabular}{l|l|l|l|r|r|r}
\hline & F1 & F2 & F3 & F4 & F5 & \multicolumn{1}{l}{ F6 } \\
\hline$P_{i}\left(D_{i}+R_{i}\right)$ & 4.221 & 3.316 & 3.172 & 3.479 & 4.027 & 4.009 \\
\hline$E_{i}\left(D_{i}-R_{i}\right)$ & -2.339 & 2.161 & 1.616 & -0.699 & -0.135 & -0.604 \\
\hline
\end{tabular}

$E_{i}(+)$ Cause Group: F2, F3

$E_{i}(-)$ Effect Group: F1, F6, F4, F5

Importance order (descending): F1, F6, F5, F4, F2, F3

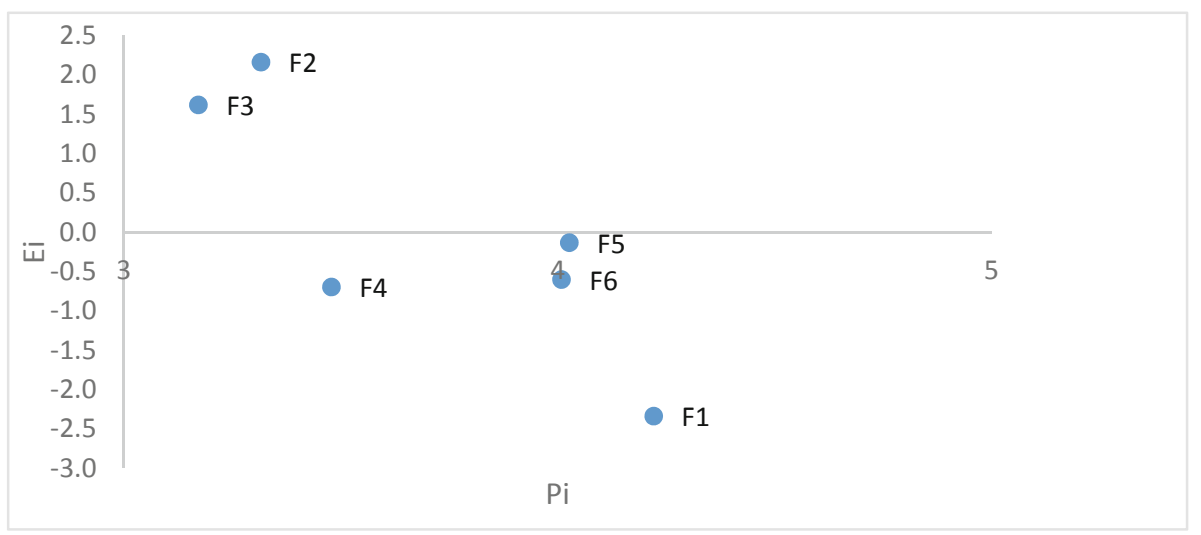

Fig. 1. The causal diagram of the factors 
As seen in Table 6, immunization-related beliefs are determined as the most influential factor of vaccine demand while urbanization is the least influential. Moreover, district-level per capita income and urbanization are indicated as the causes and the other factors as the effects. Figure 1 demonstrates cause and effect factors in a causal diagram.

\section{Managerial Insights and Concluding Remarks}

This study investigated the factors affecting the demand for vaccines that are recommended by WHO but not included in childhood immunization programs of countries. Because such vaccines are not included in national immunization programs, parents need to decide whether to get their children vaccinated. This research provides some managerial insights to decision-makers into demand factors for these types of vaccines, which are;

- Immunization-related beliefs have the greatest influence on demand forecasting among the other factors. Based on this, it can be suggested to survey parents to determine misbeliefs about these vaccines to increase the demand for such vaccines. Thus, the spread of these misbeliefs can be prevented.

- According to analysis results, district-level per capita income and urbanization are determined as the cause group. These criteria should be controlled and decisionmakers should focus more on these.

This study contains some limitations. The first limitation is the shortage of respondents. For future research, conducting more surveys to a larger number of experts is planned to ensure the validity of the research. Secondly, macro factors affecting vaccine demand is included in this analysis; future research should include macro and micro factors.

\section{References}

1. World Health Organization. https://vaccine-safety-training.org/Importance-of-immunizationprogrammes.html. Accessed 02 Mar 2020

2. World Health Organization. https://www.who.int/news-room/fact-sheets/detail/immunization-coverage. Accessed 05 Mar 2020

3. Riedel, S.: Edward Jenner and the history of smallpox and vaccination. Baylor Univ. Med. Center Proc. 18(1), 21-25 (2005)

4. Worldometers. https://www.worldometers.info/coronavirus/. Accessed 14 Apr 2020

5. OECD. http://oecd.org/economic-outlook. Accessed 05 Mar 2020

6. Ghosh, A., Laxminarayan, R.: Demand- and supply-side determinants of diphtheriapertussis-tetanus nonvaccination and dropout in rural India. Vaccine 35(7), 1087-1093 (2017)

7. Phillips, D.E., Dieleman, J.L., Lim, S.S., Shearer, J.: Determinants of effective vaccine coverage in low and middle-income countries: a systematic review and interpretive synthesis. BMC Health Serv. Res. 17, 681 (2017) 
8. Rammohan, A., Awofeso, N.: District-level variations in childhood immunizations in India: the role of socio-economic factors and health infrastructure. Soc. Sci. Med. 145, 163-172 (2015)

9. Agarwal, S.: The state of urban health in India; comparing the poorest quartile to the rest of the urban population in selected states and cities. Environ. Urban. 23(1), 13-28 (2011)

10. Kibreab, F., Lewycka, S., Tewelde, A.: Impact of mother's education on full immunization of children aged 12-23 months in Eritrea: population and health survey 2010 data analysis. BMC Public Health 20(1), 1-10 (2020)

11. Trivedi, R., Singh, S., Adhikari, P., Jatav, D.P.: Coverage evaluation of primary immunization and the associated determinants in an urban slum of Rewa, Indian. J. Community Health 26, 37-40 (2011)

12. Arokiasamy, P., Jain, K., Goli, S., Pradhan, J.: Health inequalities among urban children in India: a comparative assessment of Empowered Action Group (EAG) and South Indian states. J. Biosoc. Sci. 45(2), 167-185 (2013)

13. Akıs, S., Velıpasaoglu, S., Camurdan, A.D., Beyazova, U., Sahın, F.: Factors associated with parental acceptance and refusal of pandemic influenza A/H1N1 vaccine in Turkey. Eur. J. Pediatr. 170, 1165-1172 (2011)

14. Ciblak, M.A., Platformu, G.: Influenza vaccination in Turkey: prevalence of risk groups, current vaccination status, factors influencing vaccine uptake and steps taken to increase vaccination rate. Vaccine 31(3), 518-523 (2013)

15. Sissoko, D., Trottier, H., Malvy, D., Johri, M.: The influence of compositional and contextual factors on non-receipt of basic vaccines among children of 12-23-month old in India: a multilevel analysis. PLoS ONE 9, e106528 (2014)

16. Uddin, M.J., Larson, C.P., Oliveras, E., Khan, A.I., Quaiyum, M.M.A., Saha, N.C.: Child immunization coverage in rural hard-to-reach Haor areas of Bangladesh: possible alternative strategies. Asia Pac. J. Public Health 21(1), 8-18 (2009)

17. Shea, B., Andersson, N., Henry, D.: Increasing the demand for childhood vaccination in developing countries: a systematic review. BMC Int. Health Hum. Rights 9, 5 (2009)

18. Wu, W.W., Lee, Y.T.: Developing global managers' competencies using the fuzzy DEMATEL method. Expert Syst. Appl. 32(2), 499-507 (2007)

19. Lin, C.J., Wu, W.W.: A causal analytical method for group decision-making under fuzzy environment. Expert Syst. Appl. 34(1), 205-213 (2008)

20. Changli, F., Ma, R.: Identification of the factors that influence service innovation in manufacturing enterprises by using the fuzzy DEMATEL method. J. Cleaner Prod. 253, $120002(2020)$

21. Mokhtarian, M.N.: A note on developing global manager's competencies using the fuzzy DEMATEL method. Expert Syst. Appl. 38(7), 9050-9051 (2011)

22. Opricovic, S., Tzeng, G.H.: Defuzzification within a multicriteria decision model. Int. J. Uncertainty Fuzziness and Knowl.-Based Syst. 11(5), 635-652 (2003)

23. World Health Organization. https://www.who.int/immunization/newsroom/newsstory rotavirus_vaccines_immunization_programmes/en/. Accessed 09 Mar 2020

24. World Health Organization. https://www.who.int/gho/immunization/rotavirus/en/. Accessed 09 Mar 2020

25. Wiysonge, C.S., Uthman, O.A., Ndumbe, P.M., Hussey, G.D.: Individual and contextual factors associated with low childhood immunisation coverage in sub-Saharan Africa: a multilevel analysis. PLoS ONE 7, e37905 (2012) 